\title{
The Planetary- and Synoptic-Scale Interactions in a Southeast Pacific Blocking Episode Using PV Diagnostics
}

\author{
John P. Burkhardt And ANTHONy R. Lupo \\ Department of Atmospheric Sciences, University of Missouri, Columbia, Missouri
}

(Manuscript received 21 August 2003, in final form 12 October 2004)

\begin{abstract}
The synoptic- and planetary-scale forcing in two blocking anticyclones occurring over the southeast Pacific Ocean was examined using potential vorticity diagnostics. While many studies have examined the dynamic and thermodynamic forcing associated with blocking events in the Northern Hemisphere (NH), very few studies have examined blocking in the Southern Hemisphere ( $\mathrm{SH}$ ). Climatological analysis suggests $\mathrm{SH}$ blocking events in the Pacific region have similar characteristics to their NH counterparts. However, the occurrence of blocking is rare elsewhere in the SH, and these events are relatively short-lived. Some studies of NH blocking dynamics have also shown that the extent to which the planetary- and synoptic-scale and planetary-synoptic-scale interaction forcing that contribute to the genesis and maintenance of Pacific and Atlantic region events can be different. Thus, a study of the relevant atmospheric dynamics associated with blocking events in the $\mathrm{SH}$ was carried out in order to determine whether or not these events are associated with similar dynamic mechanisms to those in the NH. Using the National Center for Atmospheric Research and National Centers for Environmental Prediction (NCAR-NCEP) reanalyses dataset and applying a low-pass filter to the relevant variables, the authors examined the scale interactions associated with two blocking events that occurred during July and August 1986 and applied potential vorticity diagnostics. Results demonstrate that blocking in the southeast Pacific was associated with similar synoptic features, and the forcing mechanisms on the planetary, synoptic scales, and interactions were more similar to North Pacific blocking events rather than those occurring over the NH Atlantic region. However, these results also demonstrated that blocking events in the $\mathrm{NH}$ were associated with synergistically interacting synoptic- and planetary-scale waves, while in the SH, blocking events resulted from the superposition of synoptic and planetary waves. This result may explain the paucity of blocking occurrences and their tendency to be weaker and less persistent over much of the SH.
\end{abstract}

\section{Introduction}

Atmospheric blocking events and episodes have been studied extensively in the Northern Hemisphere (NH) over the past several decades in an attempt to understand the synoptic and dynamic processes that contribute to their existence, strength, and duration (e.g., Tung and Lindzen 1979; Austin 1980; Flierl et al. 1980; McWilliams 1980; Colucci et al. 1981; Shutts 1983; Colucci 1985; 1987; Tracton 1990; Lupo and Smith 1995a,b; Lupo 1997; Lupo and Smith 1998; Li et al. 1999; Lupo and Bosart 1999; Swanson 2001; Lupo 2002; Wiedenmann et al. 2002). It has been generally accepted, since earlier studies suggested it, that blocking occurs as the result of interactions between amplifying synoptic-scale waves and a quasi-stationary planetaryscale wave (e.g., Kalnay and Merkine 1981; Frederiksen

Corresponding author address: Dr. Anthony R. Lupo, Department of Soil, Environmental, and Atmospheric Sciences, 389 McReynolds Hall, University of Missouri, Columbia, MO 65211. E-mail: LupoA@missouri.edu
1982; Shutts 1983, 1986; Mullen 1986, 1987). Additionally, operationally oriented blocking studies have primarily been performed with the goal of improving medium- and long-range forecasts (e.g., Bengtssen 1981; Simmons 1986; Tibaldi et al. 1994; Li et al. 1999; Watson and Colucci 2002; Pelly and Hoskins 2003). A better understanding of blocking events would be an important element to improving medium- and long-range forecasting, as present forecast models routinely underpredict their duration and frequency (Tibaldi et al. 1994; Colucci and Baumhefner 1998; Watson and Colucci 2002; Pelly and Hoskins 2003).

Climatological studies of blocking in the Southern Hemisphere ( $\mathrm{SH}$ ) demonstrate that blocking events are less common (e.g., van Loon 1956; Lejenas 1984; Renwick 1998; Marques and Rao 2000), and are weaker (e.g., Wiedenmann et al. 2002) throughout the SH when compared to their $\mathrm{NH}$ counterparts. Wiedenmann et al. (2002) implied that the relative roles in the interaction between planetary-scale and synoptic-scale waves may partially explain the relative paucity of SH blocking. However, the same study demonstrated that blocking 
events in the South Pacific sector occur with equal frequency and persistence as those in the northern Pacific. Trenberth and Mo (1985) also suggested that the difference in climatological behavior of blocking events between the two hemispheres may be a result of differences in the dynamics that develop and maintain blocking events.

Briefly, blocking events are primarily maintained by the influx of anticyclonic vorticity advection into the blocking region by an amplifying synoptic-scale wave; however, a few studies (e.g., Tsou and Smith 1990; Alberta et al. 1991; Lupo 1997) suggested a role for temperature advections as well. The dynamic forcing mechanisms that contribute to the growth and maintenance of blocking events have also been partitioned into synoptic-scale, planetary-scale, and interaction processes in several studies as well (e.g., Tsou and Smith 1990; Tracton 1990; Mak 1991; Nakamura et al. 1997; Michelangeli and Vautard 1998; Marques and Rao 1999; Colucci 2001; Luo 2002; Watarai and Tanaka 2002). These studies have demonstrated that the importance of synoptic- and planetary-scale forcing was different for the growth and maintenance of North Atlantic and North Pacific blocking events (e.g., Nakamura et al. 1997; Colucci 2001). Nakamura et al. (1997) found that North Atlantic blocking events are primarily dependent on planetary-scale processes while North $\mathrm{Pa}$ cific events are more dependent on synoptic-scale fluxes of potential vorticity (PV) for growth and maintenance. Lupo and Smith (1995b) and Colucci (2001) found that North Atlantic blocking events were also dependent on interactions between synoptic- and planetary-scale processes. Lupo (1997) and Watarai and Tanaka (2002) also demonstrate the importance of synoptic-scale processes relative to the planetary-scale component in the North Pacific region.

Other studies have indicated that there are dynamic differences in block formation within the South Pacific region. Marques and Rao (1999) found that in the southeast Pacific region blocking episodes, zonal kinetic energy was converted into eddy kinetic energy, thus maintaining the split jet in the blocked region, while eddy kinetic energy was converted to zonal kinetic energy in the split jet regions poleward and equatorward of the block. In comparing their results with those of Trenberth (1986a,b), they found that eddies barotropically maintained the split jet, whereas in the New Zealand region (Trenberth 1986a,b) the eddies gained kinetic energy at the expense of the zonal kinetic energy. This suggests, however, that both regions are dependent on some degree of interactions between planetary- and synoptic-scale forcing during the formation phase of blocking events, but that maintenance of blocking episodes in the southeast Pacific and New Zealand region may be more dependent on synopticscale forcing.

The primary diagnostic tool to be used in this study is the PV framework, which has been generally accepted as the model of choice for explaining the growth and maintenance of various dynamical systems because it is a conserved quantity that contains all atmospheric forcing in one concise variable (e.g., Hoskins et al. 1985; Hakim et al. 1995, 1996; Morgan and Nielsen-Gammon 1998). Anticyclonic PV advection into the blocking region was found to be a key process in supporting atmospheric blocking (e.g., Illari 1984; Lupo and Bosart 1999; Colucci 2001). A PV diagnostics study and then the subsequent scale partitioning of the PV fields (following Illari 1984; Colucci 2001) have not been applied to blocking events in the SH previously.

The objective of this research is to examine two blocking events which occurred in the South Pacific during July and August 1986 in order to determine which scales predominated in the advection of PV into these two events, and then to compare the results with similar studies of NH blocking events. The hypothesis is that synoptic-scale potential vorticity advection (PVA) will be more important for $\mathrm{SH}$ blocks than it is for $\mathrm{NH}$ blocks, especially in the North Atlantic, as zonal flow in the South Pacific may not be as conducive to block formation. Then, an examination of the nature of the interactions themselves will be examined in order to determine if these interactions represent the superposition of scales only or are synergistic (nonlinear) interactions. It is also hypothesized that blocking events in the SH may need greater support from synoptic-scale forcing than a blocking event of in the NH. This scenario would be similar to the numerical study of Shutts (1983), in which synoptic-scale disturbances generated by a wavemaker were alone sufficient to generate a blocking event.

\section{Methods and analyses}

\section{a. Analyses}

The dataset used in this study was the National Centers for Environmental Prediction (NCEP) and National Center for Atmospheric Research (NCAR) gridded reanalyses (Kalnay et al. 1996). These data are archived at NCAR and were obtained from the massstore facility in Boulder, Colorado. The reanalyses used here were the $2.5^{\circ} \times 2.5^{\circ}$ latitude-longitude gridded analyses available on 17 mandatory levels from 1000 to $10 \mathrm{hPa}$ at 6-h intervals. These analyses include standard atmospheric variables such as geopotential height, temperature, relative humidity, vertical motion, $u$ and $v$ wind components, and surface information. The mandatory level data were interpolated quadratically in $\ln p$ to 50 -hPa-level increments, since these more closely resemble raw sounding information (Lupo and Bosart 1999).

\section{b. Methods}

The blocking criterion of Lupo and Smith (1995a) was used in this study, and this can be summarized as a 


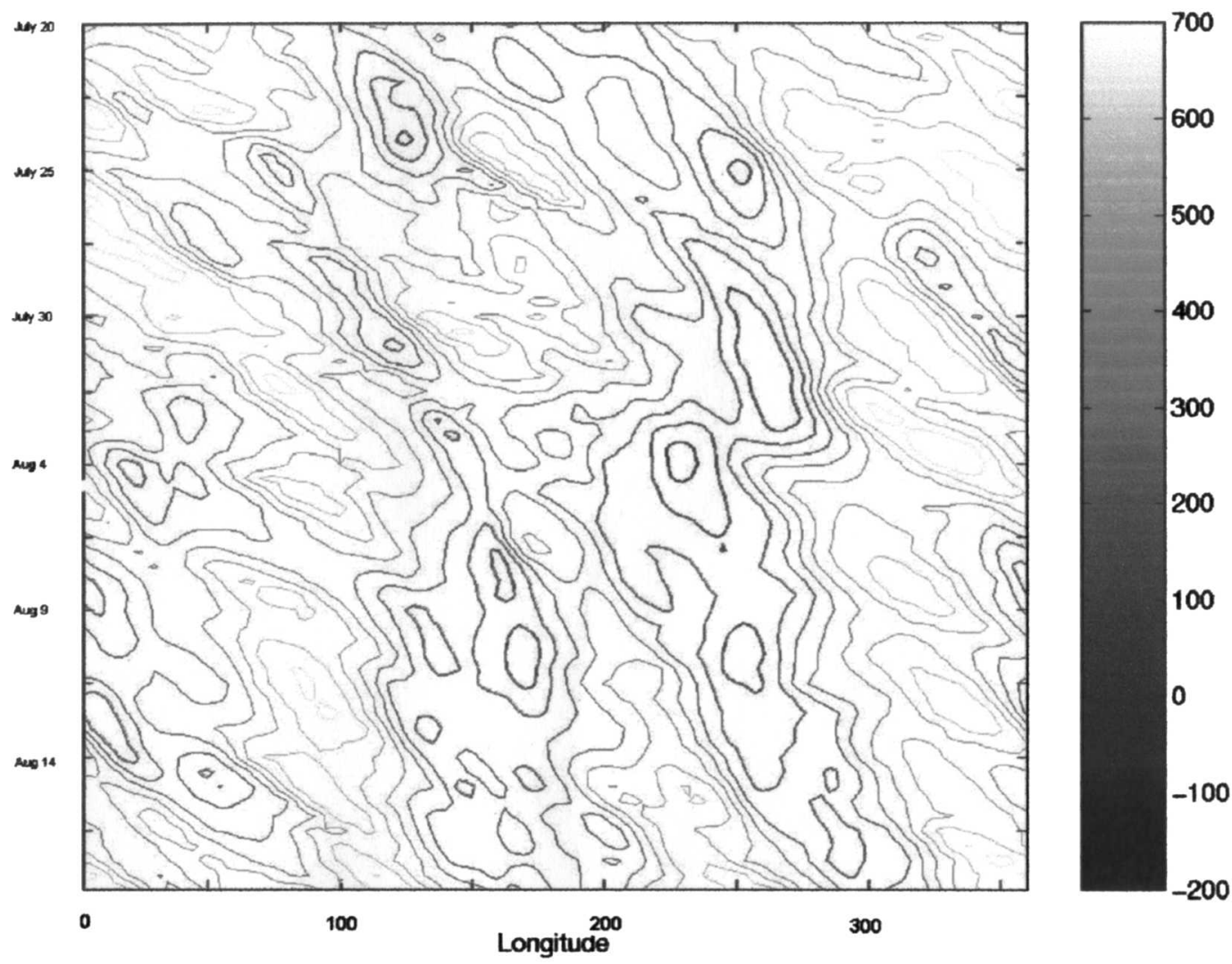

FIG. 1. A time-longitude cross section (Hovmöller 1949) of the Lejenas-Okland (LO) index for the Southern Hemisphere from 0000 UTC 20 Jul to 1200 UTC 18 Aug 1986. The darkest contour value is $-200 \mathrm{~m}$ and the contour interval is $100 \mathrm{~m}$.

combination of the Rex (1950) subjective criterion and the Lejenas and Okland (1983) objective criterion, with the exception that a "block" is defined as persisting for five days or more. The Rex (1950) criterion used subjective map analysis, and in his study it was desirable that highly meridional split flow persists for 10 days or more. The Lejenas and Okland (1983) criterion (LO) is a zonal index plotted on a time longitude or Hovmöller (1949) diagrams (Fig. 1), and persistent weak or negative "nontranslating" values can also represent blocking (Lupo and Smith 1995a). However, in Fig. 1, the Lejenas and Okland (1983) choice of latitudes for the application of the criterion was modified following Lejenas (1984) for use in the Southern Hemisphere and is presented here as

$$
\mathrm{LO}=z_{35^{\circ} \mathrm{S}}-z_{50^{\circ} \mathrm{S}},
$$

where $z$ is the 500 -hPa-height value at the indicated latitude. A more thorough description of the blocking criterion used here can also be found in Lupo and Smith (1995a), Lupo (1997), or Wiedenmann et al. (2002).
The diagnostic techniques used here are described in Lupo and Bosart (1999). Briefly, PV framework was used as the analysis and map display tool, which included the use of dynamic tropopause (DT) maps (Morgan and Nielsen-Gammon 1998). The PV was calculated on $300-\mathrm{hPa}$ surfaces since these PV fields are similar to those calculated on an isentropic surface (e.g., Bosart and Lackman 1995; Lupo and Bosart 1999; Atallah and Bosart 2003). As such, this PV calculation, although not strictly conserved, is still an effective diagnostic tool and is given here as

$$
\mathrm{PV}=g\left[\mathbf{k} \cdot\left(\frac{\partial \mathbf{V}}{\partial p} \times \nabla \theta\right)+\zeta_{a} \frac{\partial \theta}{\partial p}\right],
$$

where $\zeta_{a}$ is the magnitude of the vorticity vector along the vertical axis, $\theta$ is potential temperature, $g$ is acceleration due to gravity, and $\mathbf{V}$ is horizontal wind. Then, the change in block center point PV was calculated assuming that this quantity is conserved (e.g., Lupo and Bosart 1999). Thus, the development of a particular blocking event is equivalent to the advection of PV,

$$
\frac{\partial \mathrm{PV}}{\partial t}=-\mathbf{V} \cdot \nabla \mathrm{PV}
$$


In examining these blocking events and assessing the role of the synoptic-scale versus that of the planetaryscale forcing, the methodology of Illari (1984), Lupo and Smith (1998), or Colucci (2001, and references therein) was used. The filtered analyses were used in partitioned forms of (2) and (3) derived by substituting for each variable $X$;

$$
X=\bar{X}+X^{\prime},
$$

where the first (second) term on the right-hand side of (4) is the planetary- (synoptic-) scale component, respectively. Thus, a scale-partitioned form of (3) is given by

$$
\frac{\partial \mathrm{PV}}{\partial t}=\left.\frac{\partial \mathrm{PV}}{\partial t}\right|_{P}+\left.\frac{\partial \mathrm{PV}}{\partial t}\right|_{S}+\left.\frac{\partial \mathrm{PV}}{\partial t}\right|_{I}=P+S+I,
$$

where $P, S$, and $I$ are the planetary-scale, synopticscale, and scale interaction PV advections, respectively. The forcing term in (3), which is a product term, mathematically gives rise to scale interaction terms $(I)$ in (5) via the product rule (e.g., Colucci 2001).

A second-order, two-dimensional Shapiro (1970) filter was used 1250 times on the variables in the dataset in order to separate the planetary-scale wavelengths from the synoptic-scale wavelengths. These variables were then used to construct the PV fields. Applying a filter of this order results in a response function, which retains $2 \%, 44 \%, 80 \%$ of the signal for waves having a wavelength of 3000,4500 , and $6000 \mathrm{~km}$ at $45^{\circ} \mathrm{N}$ (or S) latitude, respectively. This response function was chosen following Lupo and Smith (1995b), since the wave in which the blocking events analyzed here were embedded had a similar length scale (about $5400 \mathrm{~km}$ or wavenumber-5) to that of Northern Hemisphere blocking events. Also, $6000 \mathrm{~km}$ represents a wavenumber between 4 and 5, thus the wave numbers (length scales) less (greater) than this can be considered to be planetary scale. More details regarding the use of the filtering procedure can be found in Lupo and Smith (1995b).

\section{Synoptic and dynamic analysis}

\section{a. Climatological comparison and synoptic analysis}

The blocking events chosen for study were two southeast (SE) Pacific region events that occurred during a blocking episode in July and August 1986. These two events occurred during a blocking episode that persisted from mid-July through mid-August and involved three separate blocking events. The climatological characteristics of the two SE Pacific events are shown in Table 1, and these blocking events were chosen for study since they occurred close together in space and time. The other event occurred over the far southwest Pacific and Australian region during the middle of Au-
TABLE 1. The climatological characteristics of the two blocking events chosen for this study (for BI see Wiedenmann et al. 2002).

\begin{tabular}{cccc}
\hline \hline Event & $\begin{array}{c}\text { Date } \\
(\text { start/termination) }\end{array}$ & Days & $\begin{array}{c}\text { Block intensity } \\
(\mathrm{BI})\end{array}$ \\
\hline 1 & 23 Jul-2 Aug & 10.5 & 3.64 \\
2 & 3-16 Aug & 13.5 & 4.06
\end{tabular}

gust (7-16 August). This time of the year represents the $\mathrm{SH}$ winter season, which is the part of the season when blocking events occur most frequently and are most persistent and strongest. These blocking events were classified as strong blocking events (e.g., Wiedenmann et al. 2002) when compared to their SH counterparts (e.g., Trenberth 1986a,b; Berbery and Núñez 1989), and can be studied as individual events since each event imparted a distinct signature on a Hovmöller plot (Fig. 1, compare to Lupo and Smith 1995a, their Fig. 1 for the Northern Hemisphere).

Blocking events in the SE Pacific have been studied by Renwick and Revell (1999), who found that Rossby wave propagation from the convectively active South Pacific convergence zone (SPCZ) region (see Vincent 1994). This suggests a strong role for the synoptic scale in block life cycles. Additionally, the two events studied here were also analyzed by Marques and Rao (1999), but using Eliassen-Palm (EP) fluxes in their diagnostics. They found that synoptic-scale transients were important contributors in the life cycle of these events. However, in their study, they examined the episode as a continuous event and did not assess in a quantitative fashion the role of the wave-wave interactions.

The development phase of this blocking event possessed all the characteristics of blocking events studied by Lupo and Smith $(1995 b, 1998)$ and references cited therein. In Fig. 2 (1200 UTC 21 July 1986), an upstream surface cyclone labeled "A" was approximately $25^{\circ}$ longitude upstream of the blocking system, which was within one-half wavelength (as suggested by Konrad and Colucci 1988; Lupo and Smith 1995a; Lupo and Bosart 1999). This cyclone event was strengthening and slowly moving poleward. At the same time, the $500-\mathrm{hPa}$ ridge was also intensifying and met the blocking criteria used here by 0000 UTC 23 July 1986. The synergistic strengthening of this cyclone and synoptic-scale wave (as shown by many of the referenced papers), the quasistationary downstream ridge, and the jet maxima on the western (and southwestern) flank of the blocking event likely contributed to enhancing the anticyclonic vorticity advection into the blocking region These signatures are key components in the development or intensification of blocking events. A second cyclone of note labeled "B" was just downstream of the developing blocking anticyclone. This slightly downstream and moderately equatorward position of the cyclone was also important for contributing to the development of 

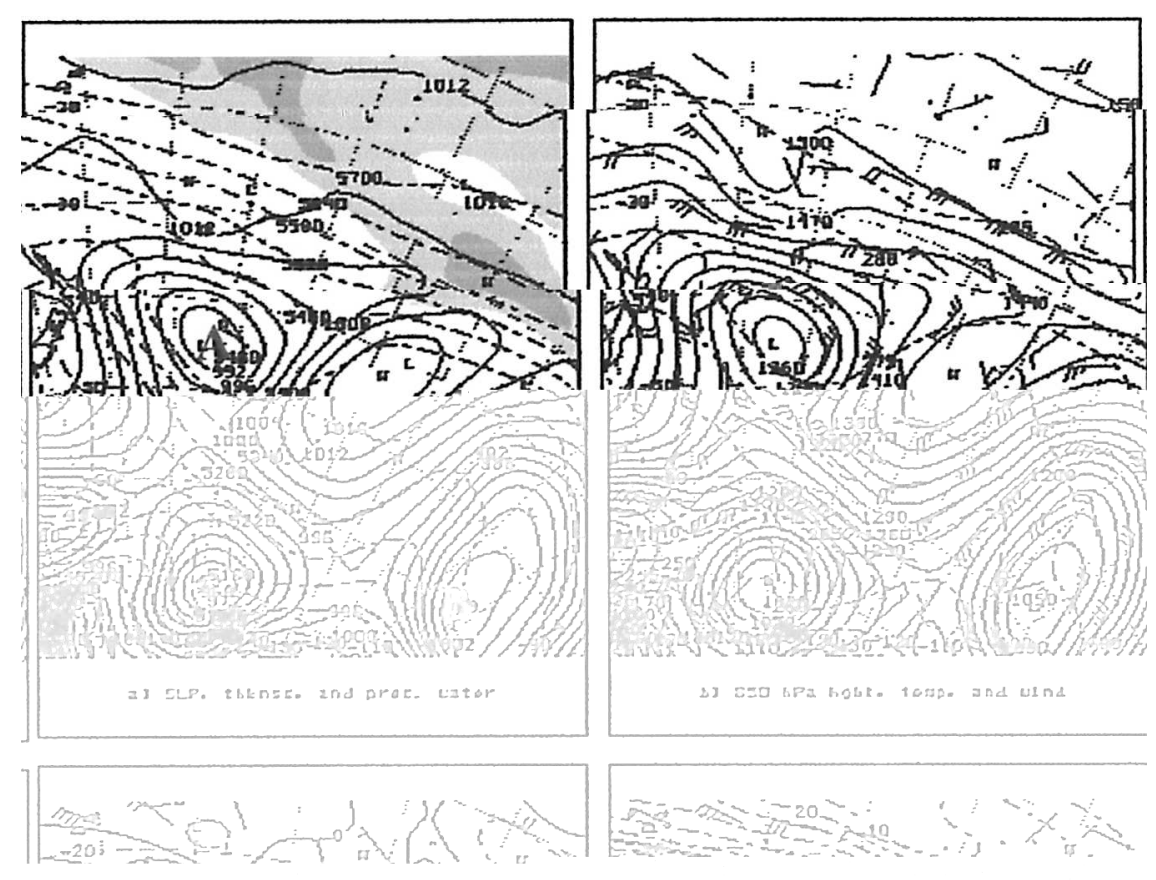

FIG. 2. Synoptic maps of (a) sea level pressure (hPa, contoured every $4 \mathrm{hPa})$, precipitable water (mm, every $12.5 \mathrm{~mm}$ ), and 1000-500-hPa thickness (m, every $60 \mathrm{~m}$ ); (b) 850-hPa height

the block because of its close proximity to the subtropical jet stream. The contribution from downstream forcing has also been suggested to play a role in block development (e.g., Tracton 1990).

During the maintenance period of this event, cyclone A remained nearly stationary, intensified, then filled in. Cyclone B moved poleward and filled. Then, two prominent cyclones $(\mathrm{C}$ and $\mathrm{D})$ developed upstream of the block around 0000 UTC 26 July, when they began to intensify and cyclone $\mathrm{C}$ moved eastward across the base (equatorward side) of the block. It reached peak intensity of roughly $986 \mathrm{hPa}$ at 1200 UTC 27 July (Fig. 3 ). The eastward movement of this cyclone across the base of the block and intensification of the blocking anticyclone (characterized by rising central heights, Fig. 4) lead to the event becoming a "blocking dipole"-a low pressure system located on the equatorward side of the block, separating the base of the block from the 

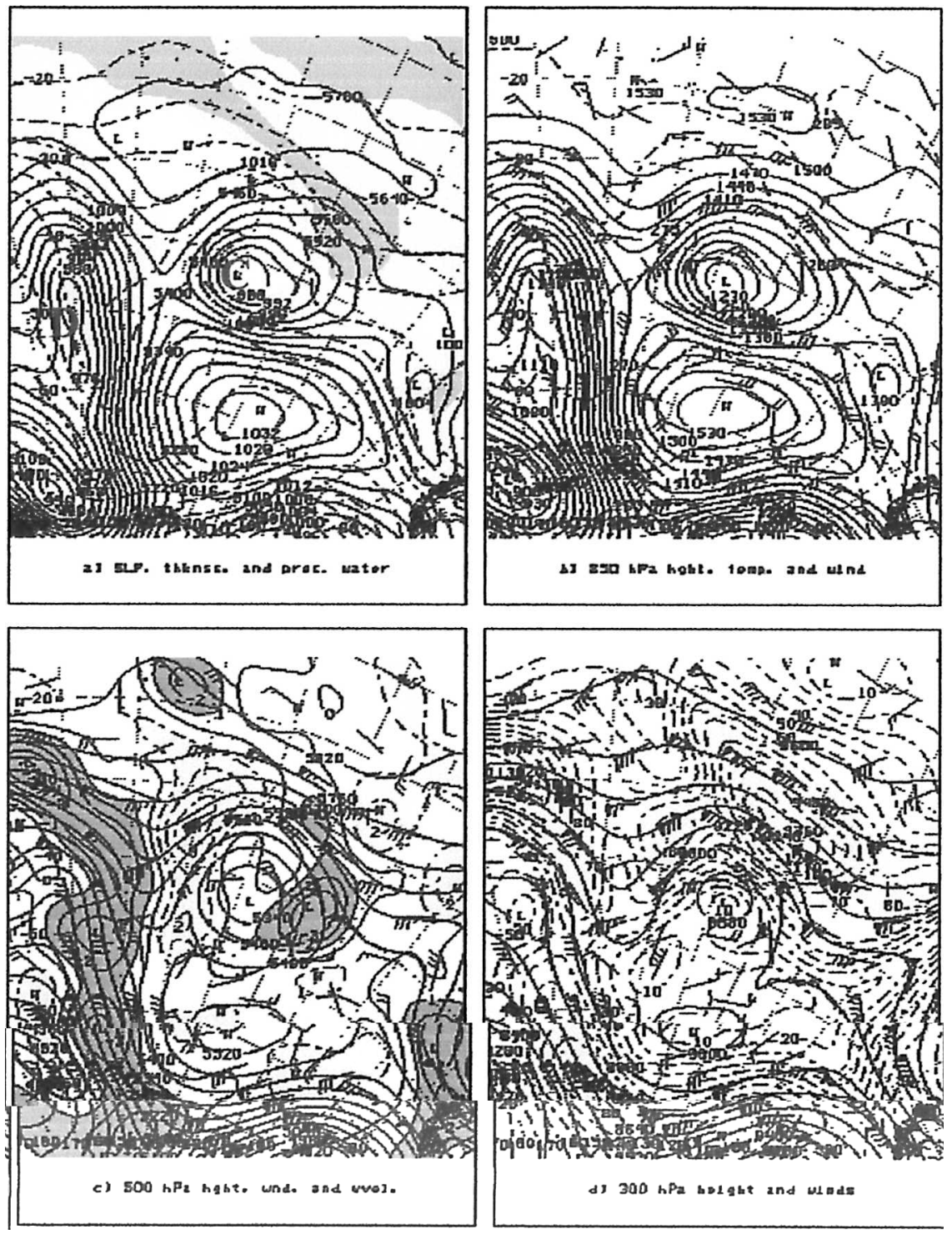

FIG. 3. As in Fig. 2, except for 1200 UTC 27 Jul 1986.

subtropical jet stream. By 0000 UTC 29 July 1986 (not shown), cyclone D moved to the downstream position originally occupied by cyclone $\mathrm{C}$ (which by then had moved eastward and poleward to the southern tip of South America), and a new upstream cyclone interacted with the west side of the block, just as cyclone "D" did before it crossed the base of the block. Again, this continued interaction with subsequent cyclones was similar to the many studies that demonstrate this interaction in NH events (e.g., Tracton 1990; Lupo 1997; Lupo and Bosart 1999).

This blocking event decayed during the latter two days of July and into August, a period that was characterized by falling central heights. The decay period was not associated with upstream cyclones. This block- ing event remained quasi-stationary during its life cycle, being located near $140^{\circ} \mathrm{W}$ at onset, and near $100^{\circ} \mathrm{W}$ during the decay period. An examination of the 12hourly 500 and $1000 \mathrm{hPa}$ synoptic maps through this period (not shown) would demonstrate that the emergence of a second event around $150^{\circ} \mathrm{W}$, or upstream of the event. This event became dominant and merged with the remaining downstream ridge (see Fig. 5). That the decaying event was not associated with upstream cyclones, which was likely due to the emergence of the second block, was similar to the decay of the Atlantic case in Lupo (1997). This type of decay differs from that described by Lupo and Bosart (1999), which described the decay of a blocking anticyclone as the result of an upstream cyclone developing in close proximity to the 


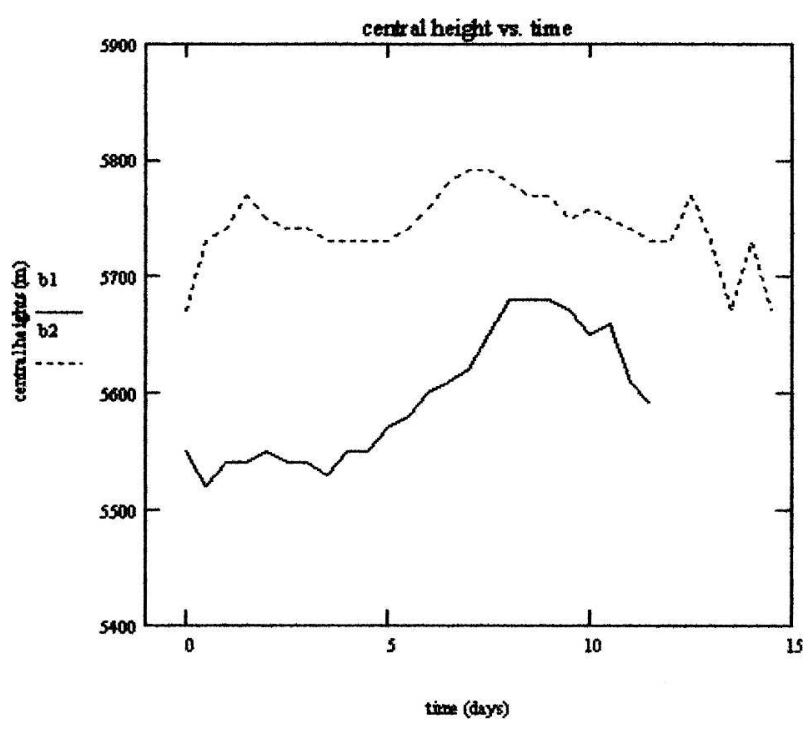

FIG. 4. A graph of central height vs time for the first blocking event (solid), and the second blocking event (dashed). Time on the abscissa is days following onset.

blocking center. Also, during the decay of their event, a prominent region of higher PV air broke off from the main reservoir and settled into the center portion of the blocking event. A similar occurrence was missing in the decay of this first event studied here.

The second blocking event began developing during the period from 1 to 3 August, and the ridging amplified poleward and expanded in scale eventually filling the region occupied by the decaying downstream ridge. To bolster the contention that this second event was a distinct event (see also Fig. 1), it was found that the event spent most of its life cycle configured as a Rextype (omega type) blocking event rather than a blocking dipole. In addition, this event was stronger overall than the first blocking event (Table 1), which is also implied by the higher central heights for this event's life cycle in Fig. 4. The central heights are proportional to block intensity (BI; see Wiedenmann et al. 2002). The dynamic analysis will also demonstrate that this event was a separate blocking event.

This blocking event underwent two intensification periods after onset (Fig. 4). The first intensification phase (3-5 August) of this block was associated with two upstream cyclones, the first of which is labeled cyclone E in Fig. 5. Figure 6 (1200 UTC 7 August 1986) corresponds to the time period just before the start of the second intensification period. Cyclone E has moved poleward and decayed, while a new cyclone $(\mathrm{F})$ began developing on the upstream side of the block. This cyclone became the dominant upstream cyclone on 8-12 August. It is interesting to note that the maximum height value of the block was attained when the upstream cyclone reached its lowest central pressure. Lupo and Smith (1995a) found a correlation between block intensity and cyclone deepening in $\mathrm{NH}$ blocking, and this occurrence suggests a similar correspondence for $\mathrm{SH}$ events.

At the beginning of the decay phase (12-16 August), a new cyclone $G$ retrograded due west to a position just equatorward of the block, creating a weak dipole situation. By 0000 UTC 15 August 1986 (Fig. 7), cyclone $\mathrm{G}$ had retrograded to a position approximately $20^{\circ}$ longitude upstream of the blocking center. This configuration is similar to that of Lupo and Bosart (1999), but different from that of the first blocking event. A brief period of height rises occurred on the 15 August when a deep ( $972 \mathrm{hPa}$ ) cyclone appeared on the upstream side of the block. However, this cyclone was also located at least $20^{\circ}$ poleward of the blocking center point and well upstream, so its relationship to the height rises in the block center may have been simply coincidental. Also, this event was similar to the decay of the Lupo and Bosart event in that several smaller-scale "pieces" of lower PV air (since PV values are negative in the Southern Hemisphere) broke off during the period and mixed with higher PV air, which may have contributed to the breakdown of this event as well.

\section{b. Dynamic analysis}

A brief analysis of the total PV tendencies will be presented here since many of the findings mirror those of previous studies. The total PV tendencies presented in Table 2 and Table 3 (and also in Tables 4 and 5) are nine-point averaged around and including center point PV tendencies calculated using Eq. (2). Using the areaaveraged tendencies is the same strategy that was used by Lupo (1997) and Lupo and Smith (1998) in their analyses using height tendency diagnostics. To filter out small-scale and computational noise, the center point tendencies were averaged over particular phases of each blocking event following, for example, Lupo (1997). They averaged height tendencies over each period using mean value theorem for definite integrals (Swokowski 1983), and using the trapezoidal method of integration.

Each phase of the block life cycle would correspond to the time- and space-averaged center-point height tendencies. Tables 2 and 3 demonstrate that, as expected, intensification (decay) periods corresponded to increasing (decreasing) $\mathrm{PV}$ values since, in the $\mathrm{SH}, \mathrm{PV}$ is a negative quantity (e.g., Lupo et al. 2001). Increasing (decreasing) $\mathrm{PV}$ in the $\mathrm{SH}$ represents the positive (negative) advection of PV in the absence of nonconservative forcing mechanisms (e.g., diabatic heating or friction) or sources and sinks of PV, and higher PV values or anticyclonic (cyclonic) PV advection are associated with block intensification (decay). A sample 500-hPa map of PV and PV advection during block intensification is shown in Fig. 8a, and positive PV ad- 

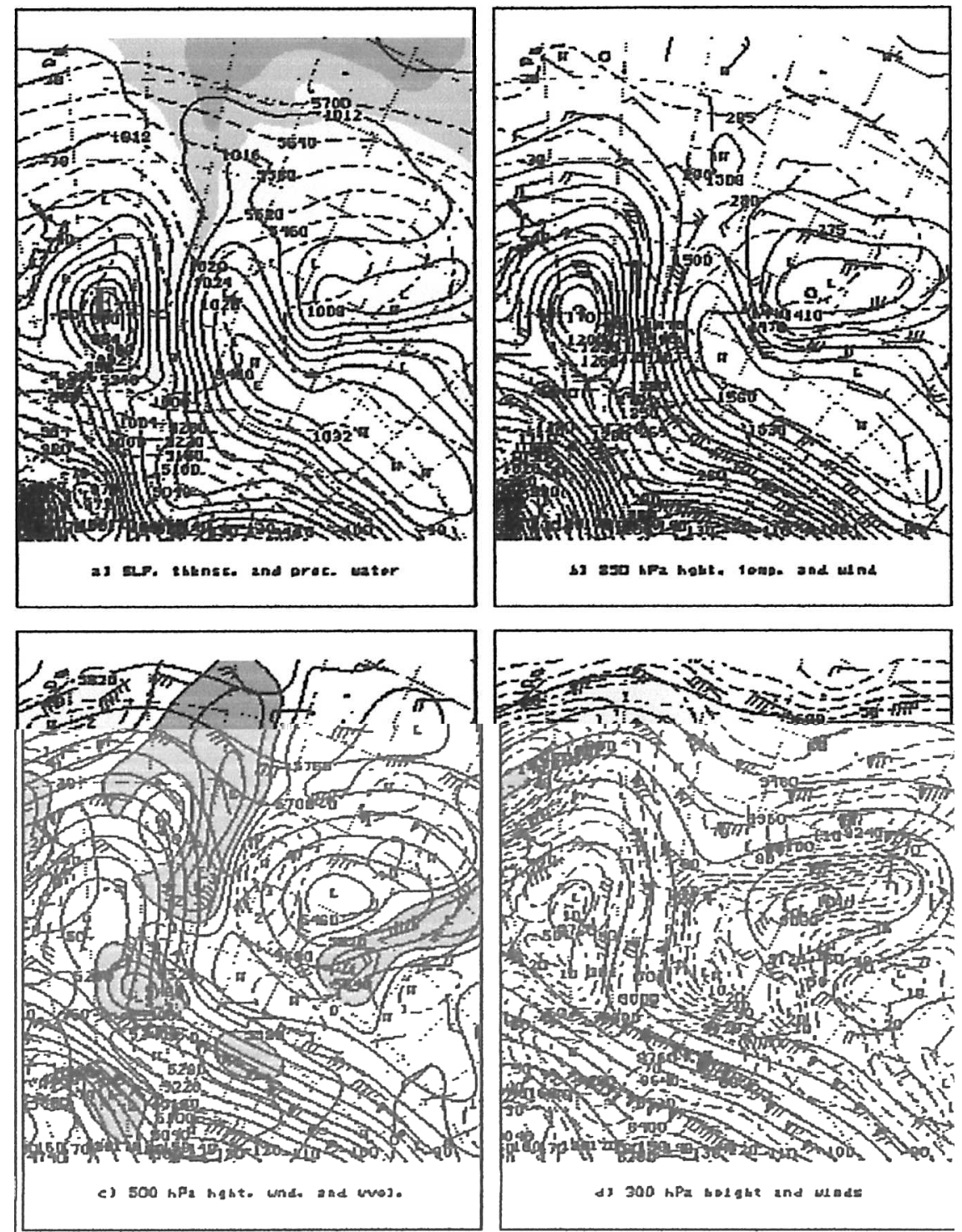

FIG. 5. As in Fig. 2, except for 0000 UTC 3 Aug 1986.

vection into the block center (in the $\mathrm{SH}$ ) was associated with block intensification. Figures $8 \mathrm{~b}$, c also imply that high $\theta$ (low pressure) advection on the dynamic tropopause (DT) were also associated with block intensification (e.g., see Lupo et al. 2001). Note that the block center was also located within the equatorward exit region of the poleward jet maximum (Fig. 8). This region would be favored for anticyclogenesis in an SH straightline model jet maximum.

When the PV tendencies were partitioned into their planetary, synoptic, and interaction components (Tables 4 and 5), the synoptic-scale PV tendencies at the block center point were generally positive contributors throughout the block life cycle, while the interaction tendencies were a negative contributor, or coun- tered the block development. The only exception to this rule occurred during the second intensification of second blocking event (Table 5). The planetary-scale PV tendencies were smaller and generally negative (positive) for the first (second) blocking event. These findings regarding the relative magnitude of the synoptic and planetary scales was also similar to those of Lupo (1997) or Lupo and Smith (1998), who found that the synoptic-scale tendencies were generally larger than those on the planetary scale for NH blocking events. These studies suggested that intensification and decay was generally governed by the combined total of the synoptic and interaction tendencies, especially for $\mathrm{Pa}-$ cific region blocking events. They also suggest that, in general, the synoptic-scale and interaction tendencies 


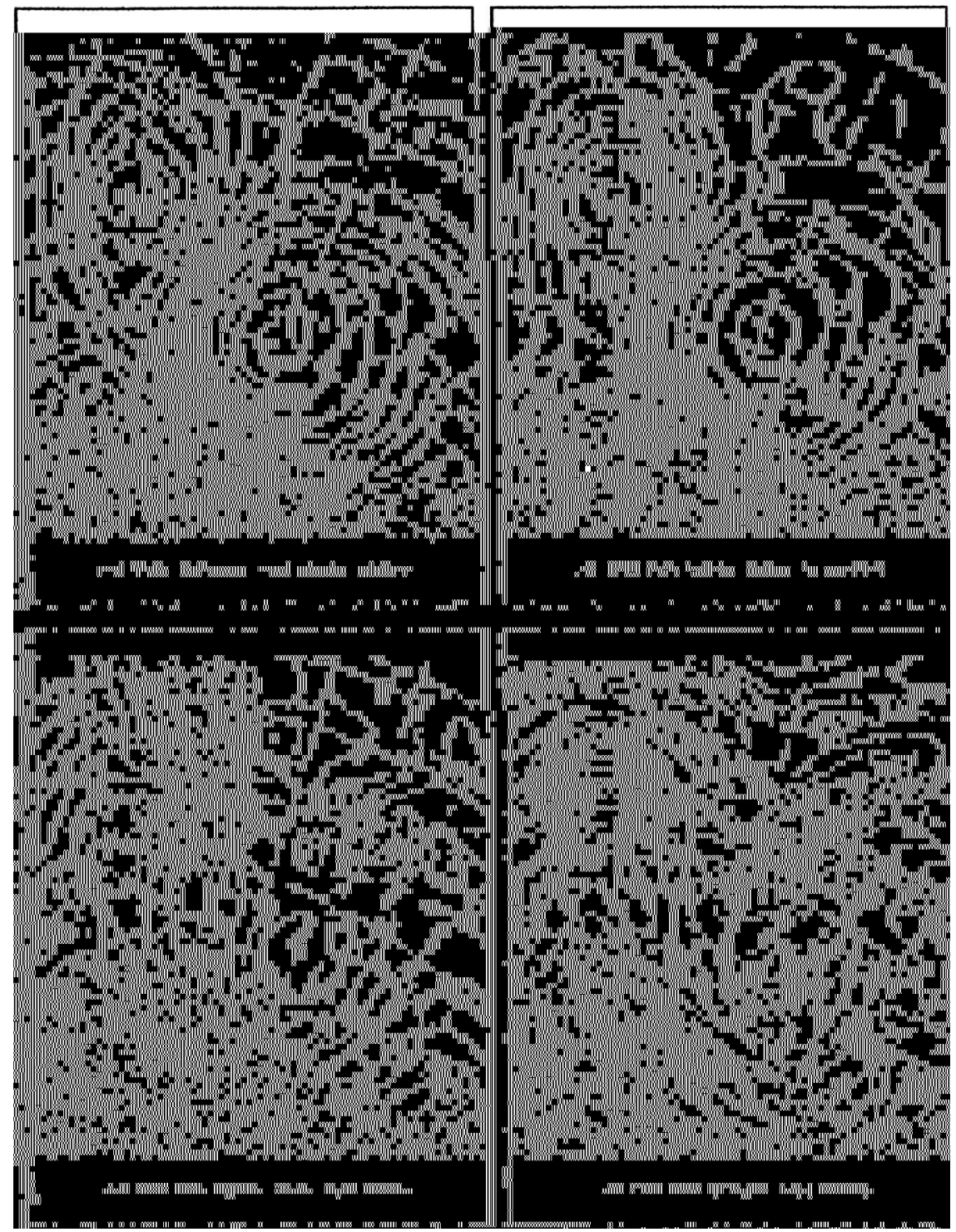

FIG. 6. As in Fig. 2, except for 1200 UTC 7 Aug 1986.

worked together, especially during the intensification periods. Their results implied that the interactions between the planetary scale and synoptic scale were synergistic. In this study, it is apparent that the synoptic scale and the interaction tendencies were of opposite sign throughout each blocking event life cycle. Thus, the interactions between the planetary and synoptic scales were not necessarily beneficial to each other in these two SH blocking events.

To investigate further the relationship between each scale in these two events, the time series of twice-daily (area averaged) center-point PV tendencies for each scale were correlated in turn against one another (Table 6) and against the total PV tendency (not shown). Only the synoptic-scale and the scale interac- tion series were highly correlated with each other, especially for the second event, and the correlation was negative. This correlation was also evident in examining plots of the PV tendencies with time throughout the block life cycles (Figs. 9a,b). The correlations are statistically significant at the $95 \%$ confidence level and these were tested using the Z-score test assuming the null hypothesis (e.g., Neter et al. 1988), or that no relationship is assumed to exist between the two a priori. It is suggested here that, unlike $\mathrm{NH}$ events, the interactions in SH blocking events may not be synergistic and this result may explain the paucity and/or the relative feebleness of SH blocking events when comparing to their NH counterparts. These issues will be further discussed below. 

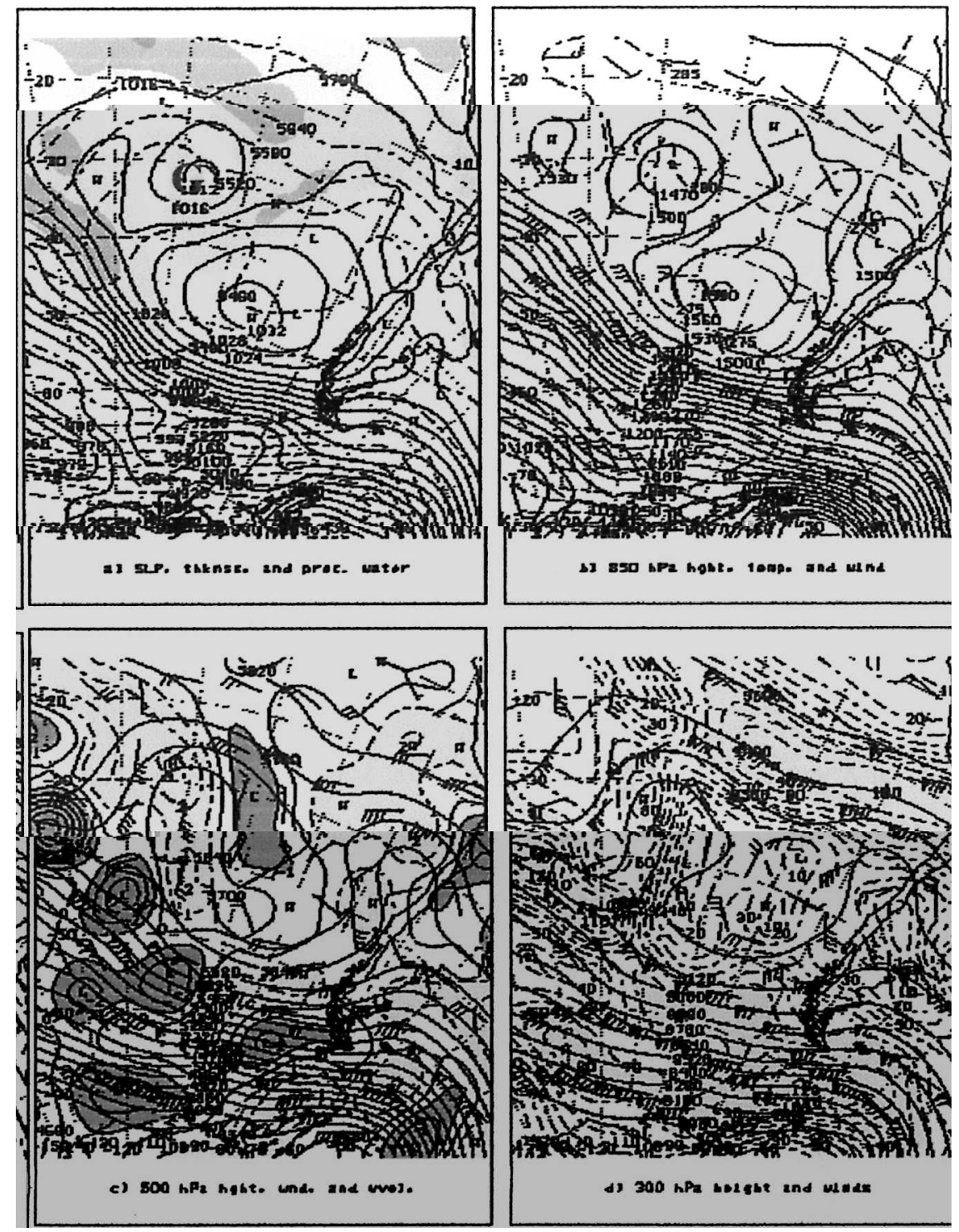

FIG. 7. As in Fig. 2, except for 0000 UTC 15 Aug 1986.

\section{Discussion}

In section 3a, it was shown that the synoptic evolution of two SH blocking events was similar to that of their $\mathrm{NH}$ counterparts in that the upstream forcing associated with the development of surface cyclones, the concurrent amplification of the associated synoptic-

TABLE 2. Average total PV $\times 10^{-7} \mathrm{PVU}$ day $^{-1}$ for each blocking phase (blocking event 1 ).

\begin{tabular}{lc}
\hline \hline \multicolumn{1}{c}{ Phase (dates covering) } & Total PV \\
\hline Preblock (20-23 Jul) & -0.70 \\
Onset/maintenance (23-28 Jul) & -3.60 \\
Intensification (28 Jul-1 Aug) & 2.90 \\
Decay (1-3 Aug) & -1.70 \\
\hline
\end{tabular}

scale upper air wave, and phase locking with a quasistationary planetary-scale wave contributed to the onset and intensification of blocking. Many of the studies referenced here have suggested that this model, which represents block onset, is associated with the influx of anticyclonic vorticity or lower potential vorticity air for the NH. Subsequent upstream cyclone development

TABLe 3. As in Table 2, except for blocking event 2.

\begin{tabular}{lr}
\hline \hline \multicolumn{1}{c}{ Phase (dates covering) } & Total PV \\
\hline Onset/intensification 1 (3-5 Aug) & 1.30 \\
Maintenance 1 (5-8 Aug) & -0.10 \\
Intensification 2 (8-11 Aug) & 8.10 \\
Maintenance 2/decay (11-16 Aug) & -2.30 \\
\hline
\end{tabular}


TABLE 4. Average scale-partitioned PV (by wavelength) and total PV $\times 10^{-7} \mathrm{PVU}_{\text {day }}{ }^{-1}$ for each blocking phase in blocking event 1 .

\begin{tabular}{lcccr}
\hline \hline \multicolumn{1}{c}{ Phase } & Synoptic-scale PV & Planetary-scale PV & Interaction PV & Total PV \\
\hline Preblock & 13.0 & 2.30 & -14.0 & -0.70 \\
Onset/maintenance & 3.50 & -3.70 & -6.40 & -3.60 \\
Intensification & 4.20 & -1.60 & -6.40 & 2.90 \\
Decay & 3.70 & -1.70 & -4.30 & -1.70 \\
Entire block & 7.60 & -1.60 & -9.40 & -0.70 \\
\hline
\end{tabular}

contributes to the further intensification of blocking events well into their lifetime, and that the same model describes the cycle of intensification and weakening often observed in longer-lived blocking events (e.g., Illari 1984; Tracton 1990; Lupo 1997; Frederiksen 1998; Lupo and Bosart 1999). Then, the synoptic evolution of these observed SH events was also similar to the early model results of Kalnay and Merkine (1981), Frederiksen (1982), or Shutts (1983), which demonstrated the importance of the contribution of synoptic transients to block formation and maintenance.

Further, an analysis of the individual upstream cyclone events during the block life cycle demonstrated that the results of Lupo and Smith (1995a) and Lupo and Bosart (1999) apply to these two SH events as well. These studies (and Konrad and Colucci 1988) suggested that cyclonic development within one-half to onequarter wavelength upstream of the block center (or ridge axis) contribute to the intensification of the event itself. In a manner similar to the blocking event studied in Lupo and Bosart (1999), synoptic-scale cyclogenesis events further upstream were too far upstream to impact block development while cyclogenesis events too close to the block center were detrimental to the maintenance of the blocking event. In the first event, decay was not associated with an upstream cyclone. Also, the decay of the second event was very similar to that of the Lupo and Bosart (1999) in that small-scale regions of low PV air broke off from the main PV reservoir and became entrained in the high $\mathrm{PV}$ region associated with the center of the block. Thus, the same key features that can be identified on routinely available maps by operational community for forecasting the onset and intensification of blocking in the $\mathrm{NH}$ can also be identified for $\mathrm{SH}$.

The synoptic analysis suggested that as long as there was upstream forcing feeding into the blocking region, the events persisted. However, that the blocking episode (and the two simultaneously individual events described in section 3) came to an abrupt end in midAugust is a question that needs further exploration. In Tables 4 and 5, the planetary-scale PV tendency contribution changed sign for each of the two successively occurring events. An examination of the PV maps for the planetary scale (not shown) indicates that, at least within the Pacific region, the planetary-scale waves did change their amplitude and propagate westward during the life cycle of each event. It is suggested here, as was suggested by Haines and Holland (1998) when they examined their model results, that blocking events may not survive the transition from one planetary-scale flow regime to another, especially if the transition in the planetary-scale flow is substantial or abrupt (as seemed to be the case during second event here, see Table 5 and the change in sign of the planetary-scale component). As they stated, this may be due to a breakdown in the planetary-scale jet stream as it becomes unstable and transitions from one regime to another. This suggests that even if the role of planetary-scale PV forcing is small, the planetary scale provides a key contribution to block maintenance even if this contribution is "preconditioning" or providing a favorable background for block development as posited by several references in this work.

An examination of the partitioned PV processes revealed that the character of the scale interactions was different when comparing $\mathrm{NH}$ blocking to $\mathrm{SH}$ events. Previous studies of the wave-wave interactions involved in blocking lifecycles focused on the large scale. For example, Austin (1980), Flierl et al. (1980), Colucci et al. (1981), Trenberth and Mo (1985), and more recently, Gottwald and Grimshaw (1999a,b) discuss blocking from the perspective of the interactions between long waves and/or solitary waves (solitons) when

TABLE 5. As in Table 4, except for blocking event 2.

\begin{tabular}{lccrr}
\hline \hline \multicolumn{1}{c}{ Phase } & Synoptic-scale PV & Planetary-scale PV & Interaction PV & Total PV \\
\hline Onset/intensification & 0.70 & 1.30 & -1.30 & 1.30 \\
Maintenance 1 & 6.80 & 2.20 & -3.20 & -0.10 \\
Intensification 2 & -13.0 & 0.00 & 11.0 & 8.10 \\
Maintenance2/decay & 8.10 & -1.00 & -5.70 & -2.30 \\
Entire block & 2.50 & 0.50 & -1.70 & 1.20 \\
\hline
\end{tabular}



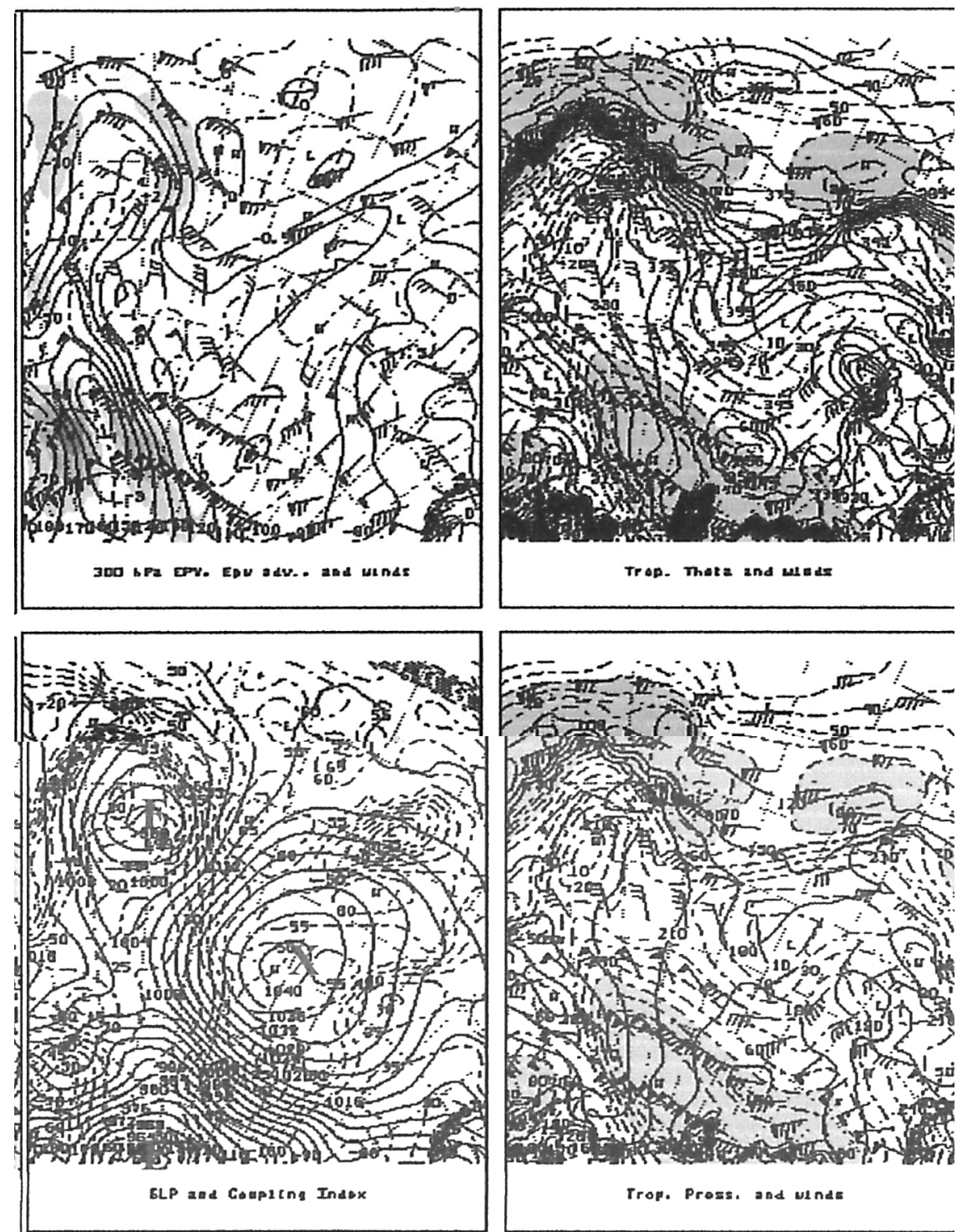

FIG. 8. Selected maps for 1200 UTC 7 Aug 1986 of (a) 300-hPa PVU (contoured every 0.5 PVU, solid), PVA (PVU s s${ }^{-1}, 0$ line contoured dashed), and wind barbs; (b) DT potential temperature (K, every $5 \mathrm{~K}$ ), winds (kt, every $10 \mathrm{kt}$ ), and wind barbs on the 2 PVU surface; (c) sea level pressure $(\mathrm{hPa}$, every $4 \mathrm{hPa}$ ), coupling index $(\mathrm{CI} ; \mathrm{K}$, every $5 \mathrm{~K})$; and $(\mathrm{d}) \mathrm{DT}$ pressure ( $\mathrm{hPa}$, every $30 \mathrm{hPa}$ ), winds (kt, every $10 \mathrm{kt}$ ), and wind barbs on the $2 \mathrm{PVU}$ surface. The shading in (a) is for the PVA beginning at \pm 4 units and progressing every 4 units. The shading in (c) is for CI values less than $10 \mathrm{~K}$, and in (b) and (d) for wind speeds greater than $70 \mathrm{kt}$. The wind barbs are as in Fig. 2. Point $\mathrm{X}$ is the block center at this time.

explaining the dynamics of blocking events. More recent studies have focused on the interactions between planetary- and synoptic-scale waves, or more specifically, the phase locking of the two scales. The studies referenced above for $\mathrm{NH}$ events suggest that the wavewave interactions between the planetary-scale wave and the amplifying synoptic-scale wave were critical for block onset or further development, and as such represent a nonlinear or synergistic amplification. This would occur if amplification or block intensification occurred such that the planetary scale, synoptic scale, and interactions all contributed positively to wave development. This is especially true for the North Pacific blocking event studied in Lupo (1997). This type of mutually beneficial wave-wave interaction between the different wave scales in the intensification of blocking events shares many of the characteristics of resonant Rossby wave triads as described by Lynch (2003), and 
TABLE 6. Correlation of scale-partitioned PV wavelengths against one another.

\begin{tabular}{cccc}
\hline \hline Scale events & Synoptic-planetary & Synoptic-interactive & Planetary-interactive \\
\hline Block 1 & 0.302 & -0.713 & -0.351 \\
Block 2 & 0.183 & -0.928 & -0.201 \\
\hline
\end{tabular}

which is analogous to a swinging spring system. However, that study also concedes that there are potential difficulties in providing an atmospheric analog to their system.

Blocking events also intensified in the $\mathrm{NH}$ as long as either the synoptic or planetary scales, along with the positive contribution from the interaction term, results in block development (e.g., Lupo and Smith 1995a; Lupo and Smith 1998; Colucci 2001). This situation would also represent a nonlinear amplification between ridges of two different scales, and the positive contribution from the synoptic scale and interactions are similar to the model and/or observational results of Bengtsson (1981), Lupo (1997), or Michelangeli and Vautard (1998) for Euro-Atlantic blocking. Thus, the onset and intensification of $\mathrm{NH}$ events are generally associated with nonlinear amplification between the two scales reflected by the positive contribution from the interaction term, and not just the superposition of the amplifying synoptic-scale wave and the quasi-stationary planetary-scale wave as they locked into phase. In either case described above, there is a mutually beneficial interaction between the scales.

This contrasts with the result found for the two $\mathrm{SH}$ events examined here. As shown in section $3 \mathrm{~b}$, the synoptic and interaction terms were generally of opposite sign throughout the block life cycles. Thus, there was generally little contribution to ridge or block development that occurred as a result of the interaction between the two scales during onset or intensification periods. In the $\mathrm{SH}$ then, blocking would appear to be generally a manifestation of the superposition between the waves of two different scales (constructive interference) as they lock into phase. Since there appears to be little (or less frequent) synergistic link between the synoptic and planetary scales, this may account for the relative infrequency of blocking in the $\mathrm{SH}$ as well as the fact they tend to be weaker and less persistent than Northern Hemisphere events as found by the climatological study of Wiedenmann et al. (2002). Also, Wiedenmann et al. (2002) find a correlation between the intensity and duration of $\mathrm{NH}$ events, which provides further evidence that the mutual wave-wave interactions in these events were beneficial to the blocking events, whereas no similar correlation found for $\mathrm{SH}$ events in that same study would support the conclusion here that these events were the result of the superposition of each scale.

\section{Summary and conclusions}

The planetary- and synoptic-scale interactions between two blocking events in the southeast Pacific Ocean region were studied here using the NCEPNCAR reanalyses and the PV system as the diagnostic tool. These two events were stronger and more persistent than typical SH events, and as such provided this study with a clear portrayal of their synoptic and dy-
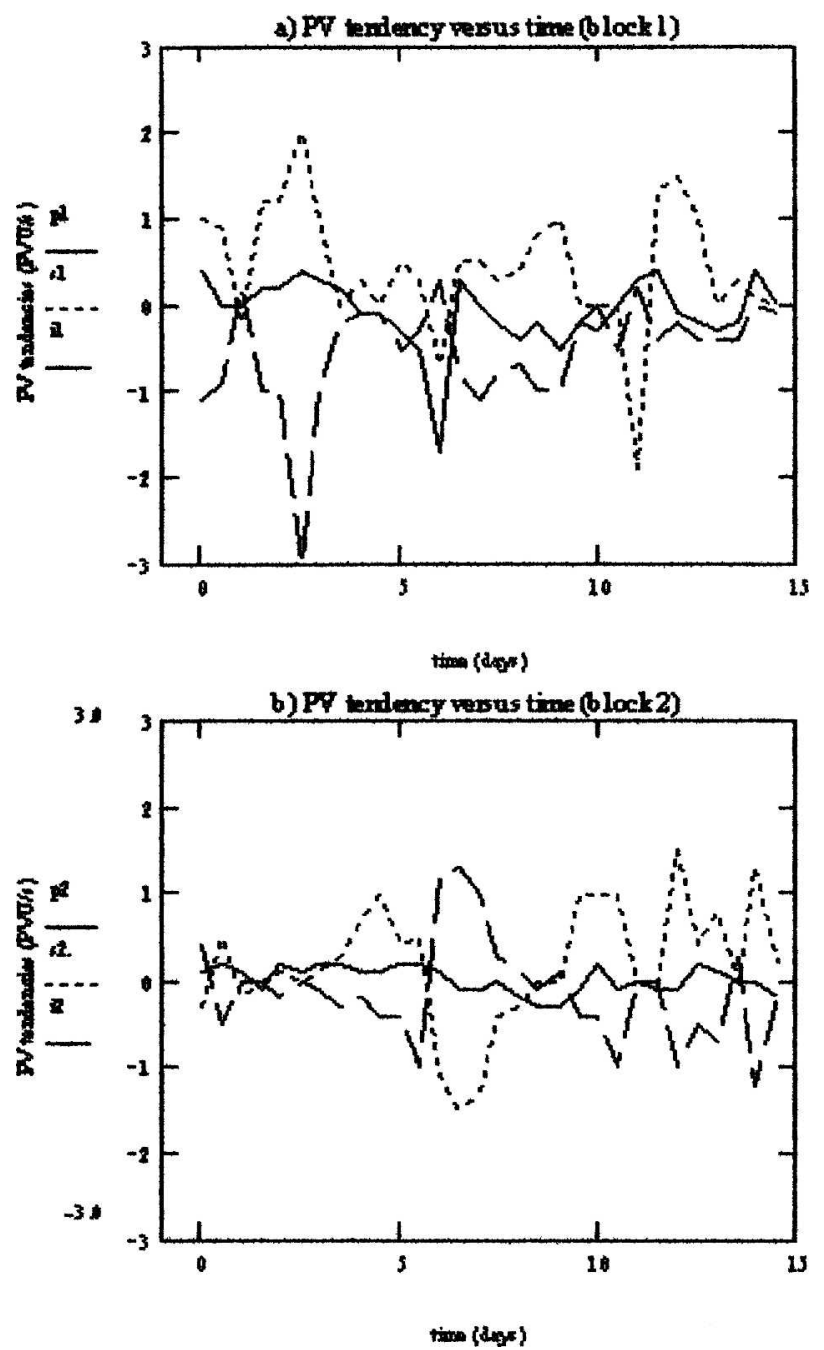

FIG. 9. A graph of PV tendencies vs time for the (a) first blocking event, and (b) the second blocking event, where the solid, dotted, and dashed lines represent the planetary scale, the synoptic scale, and the interactions, respectively. 
namic life cycle. The forcing contributing to the maintenance of these two blocking events were studied by Marques and Rao (1999), and they found that synopticscale transients made important contributions to the maintenance of these two events, and thus, only comment qualitatively on the interactions between these two events. They did not comment explicitly on the quantitative nature of the interactions, or their implications.

A synoptic analysis demonstrated that these blocking events followed the same pattern as many observational and model studies of $\mathrm{NH}$ events, or that upstream cyclogenesis and the associated synergistically amplifying short-wave phase locking with a quasistationary planetary-scale wave contributed to the onset and further intensification of these events. Block maintenance or decay occurred when there was no contribution from these upstream events, whether they occur too far upstream of the blocking event or too close to the center point. Thus, those features that can be identified in an operational environment and that contribute to the block life cycle for $\mathrm{NH}$ events can also be identified in the SH.

The dynamic analysis produced a couple of key results. First, it appeared that the SH blocking episode of July and August 1986 came to an abrupt end when the planetary-scale flow transitioned from one largescale flow regime to another that was greatly different from the blocked regime, at least within the Pacific region. This result is consistent with one of the conclusions of Haines and Holland (1998), whose model results lead them to speculate that blocking regimes may persist as long as the large-scale flow remains balanced and does not become unstable and break down or transition to a new state. Then, the importance of the planetary scale in preconditioning or providing a favorable background is confirmed for the $\mathrm{SH}$, even if the individual scale-partitioned PV tendencies are small.

A second key result is that the synoptic scale was the largest and most important contributor to block onset and maintenance. This result is similar to that found for studies of North Pacific region blocking events (e.g., Lupo 1997; or the continental region blocking event studies by Lupo and Bosart 1999), and reinforces the importance of amplifying synoptic-scale transients in the maintenance of blocking events as found by many studies for the NH.

The final key result was that, in spite of the importance of synoptic-scale transients in Pacific region blocking events, the nature of the wave-wave interactions between the planetary and synoptic scales may be different in each hemisphere. In the $\mathrm{NH}$, the interaction component of the forcing tends to be positive, suggesting that the phase locking between the planetary-scale wave and the amplifying synoptic-scale wave takes place in a nonlinear or synergistic fashion (active interaction). In these two $\mathrm{SH}$ events examined here, the interaction component of the PV tendency correlated negatively with the synoptic-scale component, and were most often opposing block intensification. This indicates that the phase locking between the scales generally resulted in the superposition of the two waves of different scales, but nothing more. In conjunction with the climatological results of Wiedenmann et al. (2002), this difference in the behavior of planetary-synoptic-scale interactions may account for the tendency of SH blocking events to occur less often, and be less persistent and intense than their NH counterparts.

Acknowledgments. The authors thank Dr. Patrick Market and Dr. Neil Fox, University of Missouri, Department of Atmospheric Sciences, and Dr. Chris Wikle, University of Missouri, Department of Statistics for their comments on earlier versions of this work. Also, we would like to give a special thank you to Dr. Wikle for his help in gaining access to the NCEPNCAR reanalysis data, and Dr. Fox for his help in drafting Fig. 1. Finally, we thank the two anonymous reviewers for their helpful suggestions in improving this manuscript.

\section{REFERENCES}

Alberta, T. L., S. J. Colucci, and J. C. Davenport, 1991: Rapid 500-mb cyclogenesis and anticyclongenesis. Mon. Wea. Rev., 119, 1186-1204.

Atallah, E. H., and L. F. Bosart, 2003: The extratropical transition and precipitation distribution of Hurricane Floyd (1999). Mon. Wea. Rev., 131, 1063-1081.

Austin, J. F., 1980: The blocking of middle latitude westerly winds by planetary waves. Quart. J. Roy. Meteor. Soc., 106, 327-350.

Bengtsson, L., 1981: Numerical prediction of atmospheric blocking-A case study. Tellus, 33, 19-42.

Berbery, E. H., and M. N. Núñez, 1989: An observational and numerical study of blocking episodes near South America. $J$. Climate, 2, 1352-1361.

Bosart, L. F., and G. M. Lackman, 1995: Postlandfall tropical cyclone reintensification in a weakly barotropic environment: A case study of Hurricane David (September 1979). Mon. Wea. Rev., 123, 3268-3291.

Colucci, S. J., 1985: Explosive cyclogenesis and large-scale circulation changes: Implications for atmospheric blocking. J. Atmos. Sci., 42, 2701-2717.

__ 1987: Comparative diagnosis of blocking versus nonblocking planetary circulation changes during synoptic scale cyclogenesis. J. Atmos. Sci., 44, 124-139.

_ 2001: Planetary-scale preconditioning for the onset of blocking. J. Atmos. Sci., 58, 933-942.

_ , and D. P. Baumhefner, 1998: Numerical prediction of the onset of blocking: A case study with forecast ensembles. Mon. Wea. Rev., 126, 773-784.

— , A. Z. Loesch, and L. F. Bosart, 1981: Spectral evolution of a blocking episode and comparison with wave interaction theory. J. Atmos. Sci., 38, 2092-2111.

Flierl, G., V. Larichev, J. McWilliams, and G. Reznik, 1980: The dynamics of baroclinic and barotropic solitary eddies. Dyn. Atmos. Oceans, 5, 1-41.

Frederiksen, J. S., 1982: A unified three-dimensional instability 
theory of the onset of blocking and cyclogenesis. J. Atmos. Sci., 39, 969-982.

, 1998: Precursors to blocking anomalies: The tangent linear and inverse problems. J. Atmos. Sci., 55, 2419-2436.

Gottwald, G., and R. Grimshaw, 1999a: The formation of coherent structures in the context of blocking. J. Atmos. Sci., 56, 3640-3662.

— of interacting solitary waves in the context of atmospheric blocking. J. Atmos. Sci., 56, 3663-3678.

Haines, K., and A. J. Holland, 1998: Vacillation cycles and blocking in a channel. Quart. J. Roy. Meteor. Soc., 124, 873-897.

Hakim, G. J., D. K. Keyser, and L. F. Bosart, 1995: The Ohio Valley wave-merger cyclogenesis event of 25-26 January 1978. Part I: A multiscale case study. Mon. Wea. Rev., 123, 2663-2692.

—, , and -1996 : The Ohio Valley wave-merger cyclogenesis event of 25-26 January 1978. Part II: Diagnosis using quasigeostrophic potential vorticity inversion. Mon. Wea. Rev., 124, 2176-2205.

Hoskins, B. J., M. E. McIntyre, and A. W. Robertson, 1985: On the use and significance of isentropic potential vorticity maps. Quart. J. Roy. Meteor. Soc., 111, 877-946.

Hovmöller, E., 1949: The trough-and-ridge diagram. Tellus, 1, 62 67.

Illari, L., 1984: A diagnostic study of the potential vorticity in a warm blocking anticyclone. J. Atmos. Sci., 41, 3518-3525.

Kalnay, E., and L. O. Merkine, 1981: A simple mechanism for blocking. J. Atmos. Sci., 38, 2077-2091.

— sis Project. Bull. Amer. Meteor. Soc., 77, 437-471.

Konrad, C. E., and S. J. Colucci, 1988: Synoptic climatology of 500-mb circulation changes during explosive cyclogenesis. Mon. Wea. Rev., 116, 1431-1443.

Lejenas, H., 1984: Characteristics of Southern Hemisphere blocking as determined from a time series of observational data. Quart. J. Roy. Meteor. Soc., 110, 967-979.

— sphere blocking as determined from a long time series of observational data. Tellus, 35A, 350-362.

Li, Z., A. Barcilon, and I. M. Navon, 1999: Study of block onset using sensitivity perturbations in climatological flows. Mon. Wea. Rev., 127, 879-900.

Luo, D., 2002: Planetary-scale baroclinic envelope Rossby solitons in a two-layer model and their interaction with synoptic-scale eddies. Dyn. Atmos. Oceans, 32, 27-54.

Lupo, A. R., 1997: A diagnosis of two blocking events that occurred simultaneously over the midlatitude Northern Hemisphere. Mon. Wea. Rev., 125, 1801-1823.

__, 2002: Ageostrophic forcing in a height tendency equation. Mon. Wea. Rev., 130, 115-126.

— anticyclones in the Northern Hemisphere. Tellus, 47A, 439456.

_ and $ـ$, 1995b: Planetary and synoptic-scale interactions during the life cycle of a mid-latitude blocking anticyclone over the North Atlantic. Tellus, 47A, 575-596.

— , and — 1998: The interactions between a midlatitude blocking anticyclone and a synoptic-scale cyclone occurring during the summer season. Mon. Wea. Rev., 126, 503-515.

- and L. F. Bosart, 1999: An analysis of a relatively rare case of continental blocking. Quart. J. Roy. Meteor. Soc., 125, 107138.

— J. J. Nocera, L. F. Bosart, E. G. Hoffman, and D. J. Knight, 2001: The occurrence of cyclonic and anticyclonic cold surges. Mon. Wea. Rev., 129, 1021-1041.

Lynch, P., 2003: Resonant Rossby wave triads and the swinging spring. Bull. Amer. Meteor. Soc., 84, 605-616.

Mak, M., 1991: Dynamic of an atmospheric blocking as deduced from its local energetics. Quart. J. Roy. Meteor. Soc., 117, 477-493.

Marques, R. F. C., and V. B. Rao, 1999: A diagnosis of a longlasting blocking event over the southeast Pacific Ocean. Mon. Wea. Rev., 127, 1761-1776.

—, and — 2000: Interannual variations of blockings in the Southern Hemisphere and their energetics. J. Geophys. Res., 105, 4625-4636.

McWilliams, J. C., 1980: An application of equivalent modons to atmospheric blocking. Dyn. Atmos. Oceans, 5, 43-66.

Michelangeli, P. A., and R. Vautard, 1998: The dynamics of EuroAtlantic blocking onsets. Quart. J. Roy. Meteor. Soc., 124, $1045-1070$.

Morgan, M. C., and J. W. Nielsen-Gammon, 1998: Using tropopause maps to diagnose midlatitude weather systems. Mon. Wea. Rev., 126, 2555-2579.

Mullen, S. L., 1986: The local balances of vorticity and heat for blocking anticylones in a spectral general circulation model. J. Atmos. Sci., 43, 1406-1441.

_ 1987: Transient eddy forcing and blocking flows. J. Atmos. Sci., 44, 3-22.

Nakamura, H., M. Nakamura, and J. L. Anderson, 1997: The role of high and low frequency dynamics and blocking formation. Mon. Wea. Rev., 125, 2074-2093.

Neter, J., W. Wasserman, and G. A. Whitmore, 1988: Applied Statistics. 3d ed. Allyn and Bacon Press, 1006 pp.

Pelly, J. L., and B. J. Hoskins, 2003: How well does the ECMWF ensemble prediction system predict blocking. Quart. J. Roy. Meteor. Soc., 129, 1683-1703.

Renwick, J. A., 1998: ENSO-related variability in the frequency of South Pacific blocking. Mon. Wea. Rev., 126, 3117-3123. , and M. J. Revell, 1999: Blocking over the South Pacific and Rossby wave propagation. Mon. Wea. Rev., 127, 2233-2247.

Rex, D. F., 1950: Blocking action in the middle troposphere and its effect on regional climate. II: The climatology of blocking action. Tellus, 2, 275-301.

Shapiro, R., 1970: Smoothing, filtering, and boundary effects. Rev. Geophys., 8, 359-387.

Shutts, G. J., 1983: The propagation of eddies in diffluent jet streams: Eddy vorticity forcing of blocking flow fields. Quart. J. Roy. Meteor. Soc., 109, 737-761.

_ 1986: A case study of eddy forcing during an Atlantic blocking episode. Advances in Geophysics, Vol. 29, Academic Press, 135-161.

Simmons, A. J., 1986: Numerical prediction: Some results from operational forecasting at ECMWF. Advances in Geophysics, Vol. 29, Academic Press, 305-338.

Swanson, K. L., 2001: Blocking as a local instability to zonally varying flows. Quart. J. Roy. Meteor. Soc., 127, 1341-1356.

Swokowski, E. W., 1983: Calculus and Analytic Geometry, Alternate Ed. PWS Publishers, 935 pp.

Tracton, M. S., 1990: Predictability and its relationship to scale interaction processes in blocking. Mon. Wea. Rev., 118, 16661695.

Trenberth, K. E., 1986a: The signature of a blocking episode on the general circulation in the Southern Hemisphere. J. Atmos. Sci., 43, 2061-2069.

_ 1986b: An assessment of the impact of transient eddies on the zonal flow during a blocking episode using localized Eliassen-Palm flux diagnostics. J. Atmos. Sci., 43, 2070-2087.

- , and K. C. Mo, 1985: Blocking in the Southern Hemisphere. Mon. Wea. Rev., 113, 3-21.

Tibaldi, S., E. Tosi, A. Navarra, and L. Pedulli, 1994: Northern and Southern Hemisphere seasonal variability of blocking frequency and predictability. Mon. Wea. Rev., 122, 19732003.

Tsou, C. H., and P. J. Smith, 1990: The role of synoptic/planetaryscale interactions during the development of a blocking anticyclone. Tellus, 42A, 174-193. 
Tung, K. K., and R. S. Lindzen, 1979: A theory of stationary long waves, Part I: A simple theory of blocking. Mon. Wea. Rev., 107, 714-734.

van Loon, H., 1956: Blocking action in the Southern Hemisphere. Notos, 5, 171-177.

Vincent, D. G., 1994: The South Pacific Convergence Zone (SPCZ): A review. Mon. Wea. Rev., 122, 1949-1970.

Watarai, Y., and H. L. Tanaka, 2002: The characteristics of barotropic-baroclinic interactions during the formation of block- ing events in the Pacific Region. J. Meteor. Soc. Japan, 80, 387-402.

Watson, J. S., and S. J. Colluci, 2002: Evaluation of ensemble predictions of blocking in the NCEP global spectral model. Mon. Wea. Rev., 130, 879-900.

Wiedenmann, J. M., A. R. Lupo, I. I. Mokhov, and E. Tikhonova, 2002: The climatology of blocking anticyclones for the Northern and Southern Hemispheres: Block intensity as a diagnostic. J. Climate, 15, 3459-3473. 